\title{
Transfer of information concerning distant foods in rats: A robust phenomenon
}

\author{
BENNETT G. GALEF, JR., DEBORAH J. KENNETT, and STEPHEN W. WIGMORE \\ McMaster University, Hamilton, Ontario, Canada
}

\begin{abstract}
Following interaction with a "demonstrator" rat, an "observer" rat prefers that diet eaten by its demonstrator prior to their interaction (Galef \& Wigmore, 1983). The present series of studies demonstrates that such demonstrator influence on observer diet preference can be found in: (1) firstgeneration laboratory bred wild rats as well as domesticated rats, (2) food-deprived as well as nondeprived observers, (3) unfamiliar as well as familiar demonstrator-observer pairs, (4) both 21-day-old and adult observers, and (5) rats selecting fluids as well as solids for ingestion. These data indicate that the social transmission of information concerning distant diets is a general and robust phenomenon, observable under a wide variety of experimental conditions.
\end{abstract}

Results of recent studies have demonstrated that during a brief period of interaction a naive rat (an observer) can extract from a recently fed conspecific (a demonstrator) information sufficient to permit observer identification of the particular food its demonstrator has eaten. This transfer of information from demonstrator to observer is evidenced by enhanced preference by observers for that diet eaten by their respective demonstrators (Galef, 1983; Galef \& Wigmore, 1983; Galef, Wigmore, \& Kennett, 1983; Posadas-Andrews \& Roper, 1983; Strupp, 1982). Such demonstrator effects on observer diet preference are not the result of simple exposure of observers to the odor of the diets eaten by their respective demonstrators. Demonstrator influence on observer diet preference requires that an observer experience a diet in the context of stimuli (as yet undefined) provided by the presence of a conspecific. Thus, it seems appropriate to think about demonstrator influence on observer diet preference as reflecting a rudimentary form of communication or information transmission from one individual to another. The occurrence of such communication might be inhibited by any of a number of factors.

Although transmission between rats of information concerning distant diets has been demonstrated in a number of laboratories, each using somewhat different procedures, there has been no systematic exploration of the range of experimental conditions under which social transmission of diet preference occurs. The published literature thus leaves unanswered questions as to the robustness and generality of the phenomenon. In the experiments reported below, we examine the effects of subject genotype, sub-

This research was suppored by Natural Sciences and Engineering Research Council of Canada Grant AP-307 and a McMaster University Research Board grant to B.G.G., Jr. We thank Sandra Vegeris for technical assistance. D. J. Kennett is now at Trent University, and S. W. Wigmore is at the University of Western Ontario.

Bennett G. Galef, Jr.'s mailing address is: Department of Psychology, McMaster University, Hamilton, Ontario, Canada L8S 4K1. ject age, subject motivational state, demonstrator-observer familiarity, and the nature of the ingesta selected by observers on the transmission of preference for distant diets.

\section{GENERAL METHOD}

\section{Subjects}

Subjects in all experiments described below were same-sex demonstrator-observer pairs of rats. Except as otherwise noted, the observers were experimentally naive 42-day-old Long-Evans rats obtained from Blue Spruce Farms (Altamont, NY) and the demonstrators were 90-day-old rats that had served as observers some weeks earlier.

\section{Apparatus}

The subjects were housed and tested as demonstrator-observer pairs in $42.5 \times 24 \times 27.5 \mathrm{~cm}$ wire-mesh hanging cages (Wahmann Co., Baltimore). Each cage was divided into two equal parts by a $1.25-\mathrm{cm}$ $(1 / 2$-in.) wire-mesh partition $(24 \times 27.5 \mathrm{~cm})$ attached at the midpoints of each cage's $42.5-\mathrm{cm}$ sides.

Treatment of subjects during experiments was as follows (see Figure 1):

Step 1: To permit familiarization with both apparatus and partner, each demonstrator-observer pair was maintained together, with ad-lib access to Purina Laboratory Rodent Chow pellets (their normal maintenance diet), and left undisturbed for 2 days.

Step 2. To ensure that demonstrators ate when given the opportunity to do so, each demonstrator was moved to the opposite side of the screen partition from its observer and food deprived for $24 \mathrm{~h}$.

Step 3: In preparation for the testing of observers, chow was removed from each observer's side of the apparatus. Each demonstrator was then moved to an individual enclosure in a room separate from that housing the apparatus and allowed to feed for $30 \mathrm{~min}$ on either powdered Purina Laboratory Rodent Chow adulterated $2 \%$ by weight with sifted Hershey's Pure Cocoa (cocoa-flavored diet) or powdered Purina Laboratory Rodent Chow adulterated $1 \%$ by weight with McCormick's Fancy Ground Cinnamon (cinnamon-flavored diet).

Step 4: Each demonstrator was returned to its observer's cage, and demonstrator and observer were allowed to interact freely for $15 \mathrm{~min}$.

Step 5: Demonstrators were removed from the experiment, and each observer was offered, for $24 \mathrm{~h}$, two weighed food cups, one containing cinnamon-flavored diet and one containing cocoa-flavored diet. At the termination of an experiment, the experimenter weighed both food cups and calculated the diet intakes of the observers. 


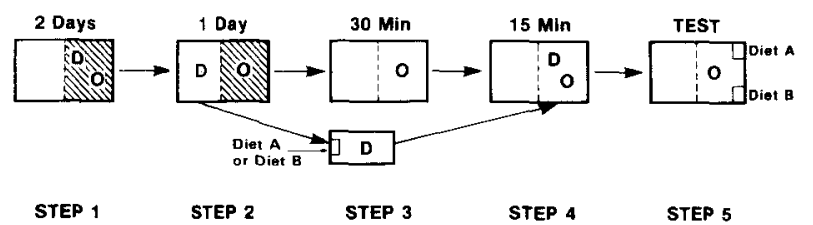

Figure 1. Schematic diagram of general procedure. $(\mathrm{O}=$ observer; $D=$ demonstrator; hatching indicates that pellets of Purina Laboratory Rodent Chow were present in cage).

\section{EXPERIMENT 1}

The present experiment followed the General Method exactly. The only deviation from our normal procedures was that all demonstrators and observers were same-sex sibling pairs of first-generation laboratory-bred wild rats (Rattus norvegicus). Although there was no strong reason to predict that wild rats would not behave like domesticated individuals in our paradigm, the exaggerated response of genetically wild rats to novel foods (Barnett, 1958; Galef, 1970) might obscure demonstrator effects on observer diet preference.

\section{Method}

Subjects. Ten male and 10 female 42 - to 50 -day-old first-generation laboratory-bred wild rats, descendants of animals live-trapped on a farm in West Flamborough, Ontario, served as observers. Twenty of their siblings served as demonstrators.

\section{Results and Discussion}

Those observers whose demonstrators ate cocoaflavored diet ate a greater percentage of cocoa-flavored diet $(62.4 \%)$ during testing than did those observers whose demonstrators ate cinnamon-flavored diet (17.3\%) (MannWhitney $\mathrm{U}=8$, both $\mathrm{ns}=9, .001<\mathrm{p}<.01)$.

The results clearly demonstrate that wild rat observers are influenced in diet selection by foods previously ingested by conspecifics with whom those observers interacted. Taken together with our previous demonstrations of demonstrator influence on observer diet preference in domesticated rats, the present data suggest that such social effects on diet preference are exhibited by a variety of strains of rat. The demonstration that wild rats exchange information concerning distant diets strengthens arguments (Galef \& Wigmore, 1983) that the mode of social influence under investigation may be used by rats in natural circumstances.

\section{EXPERIMENT 2}

In all our previous studies, observer rats have been allowed to both interact with demonstrators and choose between test diets within $45 \mathrm{~min}$ of their removal from ad-lib access to food. In the present experiment, observers were 24-h food deprived, both when they interacted with demonstrators and when they were subsequently tested for diet preference. It seemed intuitively plausible that food-deprived observers might be less sen- sitive to subtle differences in the flavor of available diets than recently fed observers and might, therefore, be less influenced in their diet selection by interaction with demonstrators than such nondeprived observers.

\section{Method}

Subjects. The subjects were 16 male and 16 female 42 -day-old LongEvans rat pups. An additional 3290 -day-old rats served as demonstrators. Observers and demonstrators were randomly assigned to food-deprived and nondeprived groups, whose treatment is described below.

Procedure. Demonstrators and observers assigned to the nondeprived group were treated as described in General Method. Those assigned to the food-deprived group were treated exactly like those in the nondeprived group, except that the observers as well as the demonstrators were food deprived for $24 \mathrm{~h}$ in Step 2 of the procedure (see Figure 1).

\section{Results and Discussion}

The main results of Experiment 2 are presented in Figure 2 , which shows the mean amount of cocoa-flavored diet, as a percentage of total amount eaten, ingested by nondeprived and food-deprived observers whose demonstrators had eaten either cocoa-flavored or cinnamon-flavored diet during Step 3 of the experiment (see Figure 1). Figure 2 shows the intake of the observers both 6 and $24 \mathrm{~h}$ after initiation of testing. As is clear from examination of the figure and as statistical tests confirmed (Mann-Whitney $U$ tests; see Figure 2 for $U$ and $p$ values), both nondeprived and food-deprived observers exhibited a preference for their respective demonstrators' diets both 6 and $24 \mathrm{~h}$ after initiation of testing. The extraction and use by observers of diet cues emitted by demonstrators seem to be relatively independent of observer state of deprivation.

\section{EXPERIMENT 3}

In our previously published work on social transmission of information concerning distant diets, we have allowed demonstrators and observers to become familiar with one another (see Step 1 of Figure 1) prior to providing an opportunity for information transmission. The present experiment was undertaken to determine whether such demonstrator-observer familiarity is a necessary condition for demonstrator influence on observer diet preference. It seemed plausible that during a brief period of interaction, unfamiliar demonstrator-observer pairs might be more concerned with individual identification or establishment of dominance than with communication of dietary information and that the former activities might interfere with the latter.

\section{Method}

Subjects. Thirty-two 42-day-old Long-Evans rats served as observers, and an additional 32 90-day-old rats of the same strain served as demonstrators. Observers and demonstrators were assigned randomly to Familiar and Unfamiliar groups.

Procedure. Observers and demonstrators assigned to the Familiar group were treated exactly as were subjects described in General Method. The observers and demonstrators assigned to the Unfamiliar group were treated exactly as were subjects in the Familiar group, except that individual demonstrators were introduced into the experimental apparatus 


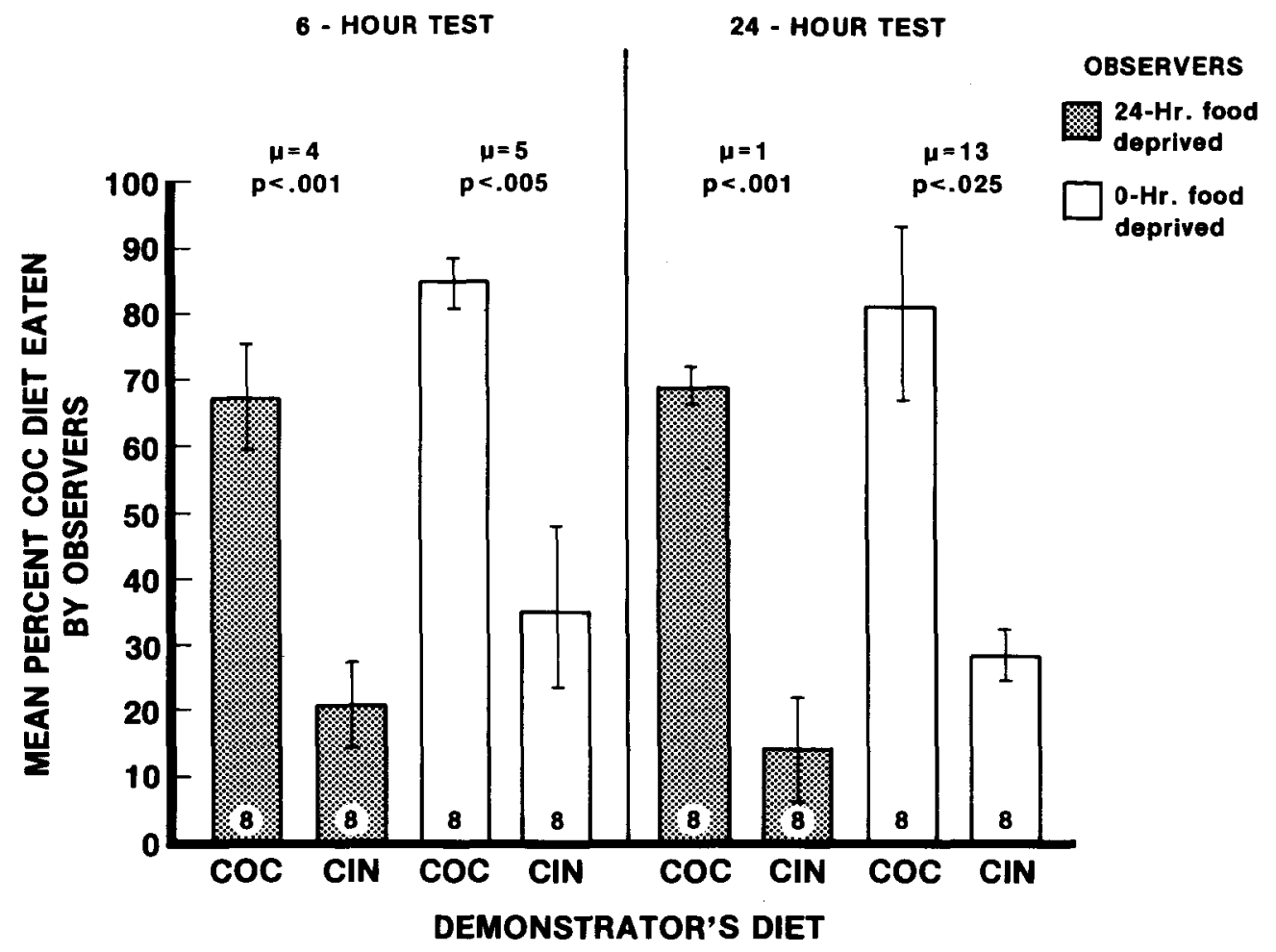

Figure 2. Mean amount of cocoa-flavored diet ingested, as a percentage of total amount eaten, by fooddeprived and satiated observers. Left-hand panel, 6-h test; right-hand panel, 24-h test. (Bars indicate $\pm 1 \mathrm{SE}$; Cin =cinnamon-flavored diet; $\mathbf{C o c}=$ cocoa-flavored diet; numbers inside bars indicate group size).

only during the $15 \mathrm{~min}$ of interaction of demonstrators and observers (Step 4 of Figure 1). While observers assigned to the Unfamiliar group were undergoing Steps I to 3 of General Method (see Figure 1), their respective demonstrators were maintained in pairs in polypropylene bucket cages in a colony room and food deprived for the $24 \mathrm{~h}$ immediately prior to their interaction with the observers.

\section{Results and Discussion}

The results of Experiment 3 are presented in Figure 3, which shows the mean amount of cocoa-flavored diet, as a percentage of total amount ingested, eaten by observers in the Familiar and Unfamiliar groups whose demonstrators ate cocoa- or cinnamon-flavored diet. Observers, regardless of whether they were familiar with their respective demonstrators, exhibited a markedly enhanced preference for their respective demonstrators' diets (Mann-Whitney $U$ tests; see Figure 3 for $U$ and $p$ values). Familiarity between demonstrator and observer is not a prerequisite for transmission of diet preference.

\section{EXPERIMENT 4}

In some of our previous work on social transmission of feeding site selection, we have found large differences in the impact of social interaction on the selection of feeding as compared with drinking sites (Galef, 1978). Although the presence of an adult rat at a feeding site profoundly influenced a conspecific weanling's probability

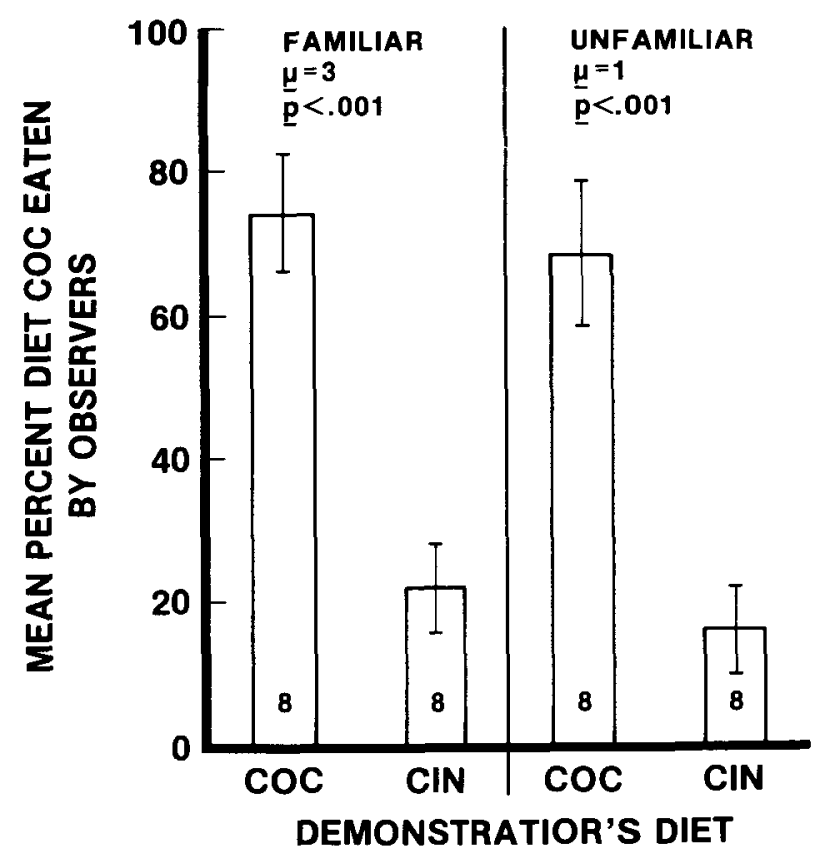

Figure 3. Mean amount of cocoa-flavored diet ingested, as a percentage of total amount eaten, by observers in Familiar and Unfamiliar demonstrator-observer pairs. (Bars indicate $\pm 1 \mathrm{SE}$; Cin =cinnamon-flavored diet; $\mathbf{C o c}=$ cocoa-flavored diet; numbers inside bars indicate group size.) 
of eating there, the presence of an adult rat at a drinking site did not have a comparable effect on weanlings' choice of a site at which to drink. These data suggest that social influence may be more important in directing the behavior of rats selecting foods than of rats selecting liquids for ingestion. The present experiment was undertaken to determine whether rats would utilize information from conspecifics in selecting a liquid to ingest.

\section{Method}

Subjects. Eighteen male and 18 female 42-day-old Long-Evans rat pups served as observers in the present experiment. An additional 36 90-day-old rats were used as demonstrators.

Procedure. The procedure of the present experiment was identical to that described in General Method, except that (1) demonstrators were both food and water deprived during Step 2 of General Method (see Figure 1), and (2) during Steps 3 and 5 of General Method (see Figure 1), the ingesta offered demonstrators and observers differed from those discussed in General Method.

During Step 3 of the present experiment, half the demonstrators had access to a coffee-flavored solution ( $2.1 \% \mathrm{wt} / \mathrm{vol}$, Sanka Decaffeinated Instant Coffee) and the other half had access to a vinegar-flavored solution (3.2\% vol/vol, Allen's Pure Apple Cider Vinegar).

During Step 5, half the observers were offered a choice between coffeeand vinegar-flavored solutions and half a choice beteween coffee- and vinegar-flavored mashes (coffee-flavored mash-235 $\mathrm{cc}$ tap water plus $9.4 \mathrm{~g}$ Sanka Decaffeinated Instant Coffee mixed with $200 \mathrm{~g}$ Five Roses White Enriched Flour; vinegar flavored mash-235 $\mathrm{cc}$ tap water plus 14.1 cc Allen's Pure Apple Cider Vinegar mixed with 200 g Five Roses White Enriched Flour).

To control for evaporation of both solutions and both mashes during Step 5 of the experiment, at the initiation of observer testing (Step 5 of Figure 1), three weighed samples of each solution and each mash were placed in empty cages in the experimental room. At the termination of testing, each of these 12 control samples was weighed, the mean weight loss for each of the four types of sample was calculated, and the appropriate corrections were made prior to the calculation of mash or fluid intakes by the observers.

\section{Results and Discussion}

The results of Experiment 4 are presented in Figure 4, which shows the mean amount of coffee-flavored substances, as a percentage of total amount ingested, ingested by observers whose demonstrators drank coffeeor vinegar-flavored solution. The observers exhibited enhanced preference for ingesta of the same flavor as that which their respective demonstrators had consumed, regardless of whether those observers were choosing between fluids or mashes (Mann-Whitney $U$ tests; see Figure 4 for $U$ and $p$ values). In the present situation, observers used information extracted from demonstrators in selecting fluids as well as solids for ingestion.

\section{EXPERIMENT 5}

Previous studies of social influence on feeding site selection by adult and weanling domesticated rats have revealed that social interaction is a more potent factor in influencing the feeding site selection of juvenile rats than of adults (Galef, 1977b). It therefore seemed reasonable to inquire whether the utilization of information concerning distant diets varied as a function of the age of demonstrators and observers.

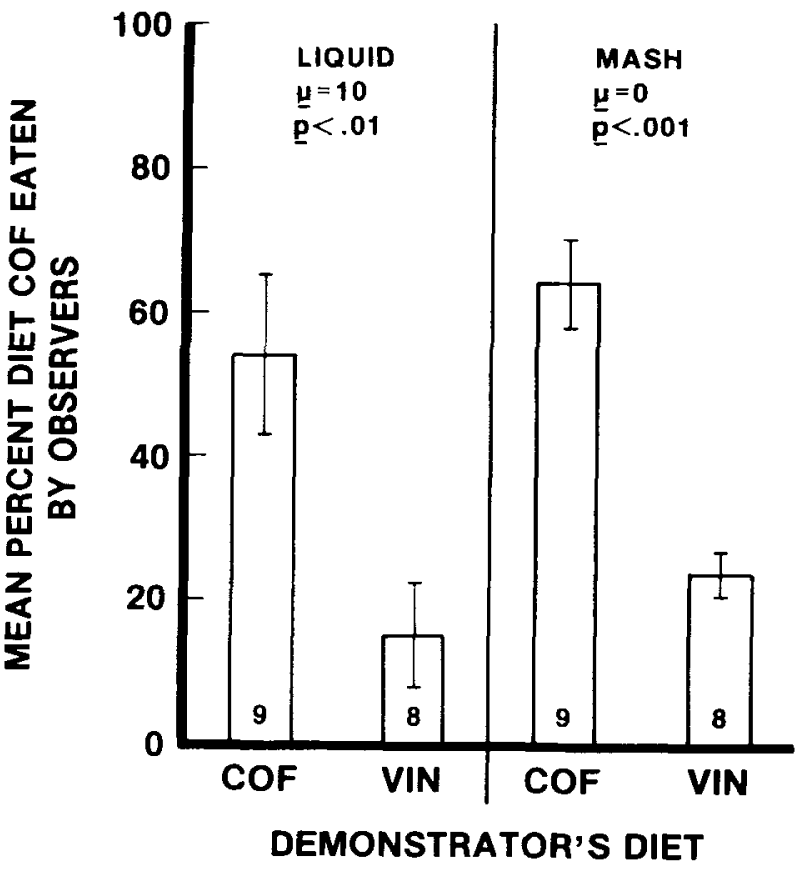

Figure 4. Mean amount of coffee-flavored substances ingested, as a percentage of total amount ingested, by observers offered fluids and mashes. (Bars indicate $\pm 1 \mathrm{SE}$; Cof=coffee-flavored; Vin = vinegar-flavored; numbers inside bars indicate group size.)

\section{Method}

Subjects. Forty female Long-Evans 21 -day-old rat pups and 60 adult females of the same strain (200-250 g) served as observers. An addi tional 6021 -day-old pups and 40 adult females (200-250 g) served as demonstrators. The subjects were assigned to one of four groups dif fering in the ages of demonstrators and observers. Adopting a terminology in which a group with 21-day-old demonstrators and 225-g observers is described as 21:225, the four groups employed were $21: 21$, $21: 225,225: 21$, and $225: 225$.

Procedure. The procedure was that described in General Method, except that in order to inhibit the tendency of adult rats to attack juveniles, it proved necessary to place adults paired with juveniles into the apparatus (Step 1 of Figure 1) several hours before their juvenile pairmates were placed there.

\section{Results and Discussion}

The results of Experiment 5 are presented in Figure 5, which shows the mean amount of cocoa-flavored diet, as a percentage of total amount ingested, eaten by the observers in Groups 21:21, 21:225, 225:21, and 225:225, whose demonstrators ate a cocoa- or cinnamon-flavored diet. In all cases, the observers exhibited an enhanced preference for the diet their respective demonstrators ate (Mann-Whitney $U$ tests; see Figure 5 for $U$ and $p$ values). The only age-related trend in the data, and it did not approach significance, was for the 225-g observers to be less influenced in their diet selection by demonstrators than 21-day-old observers.

\section{GENERAL DISCUSSION}

The results of the present series of studies indicate that 


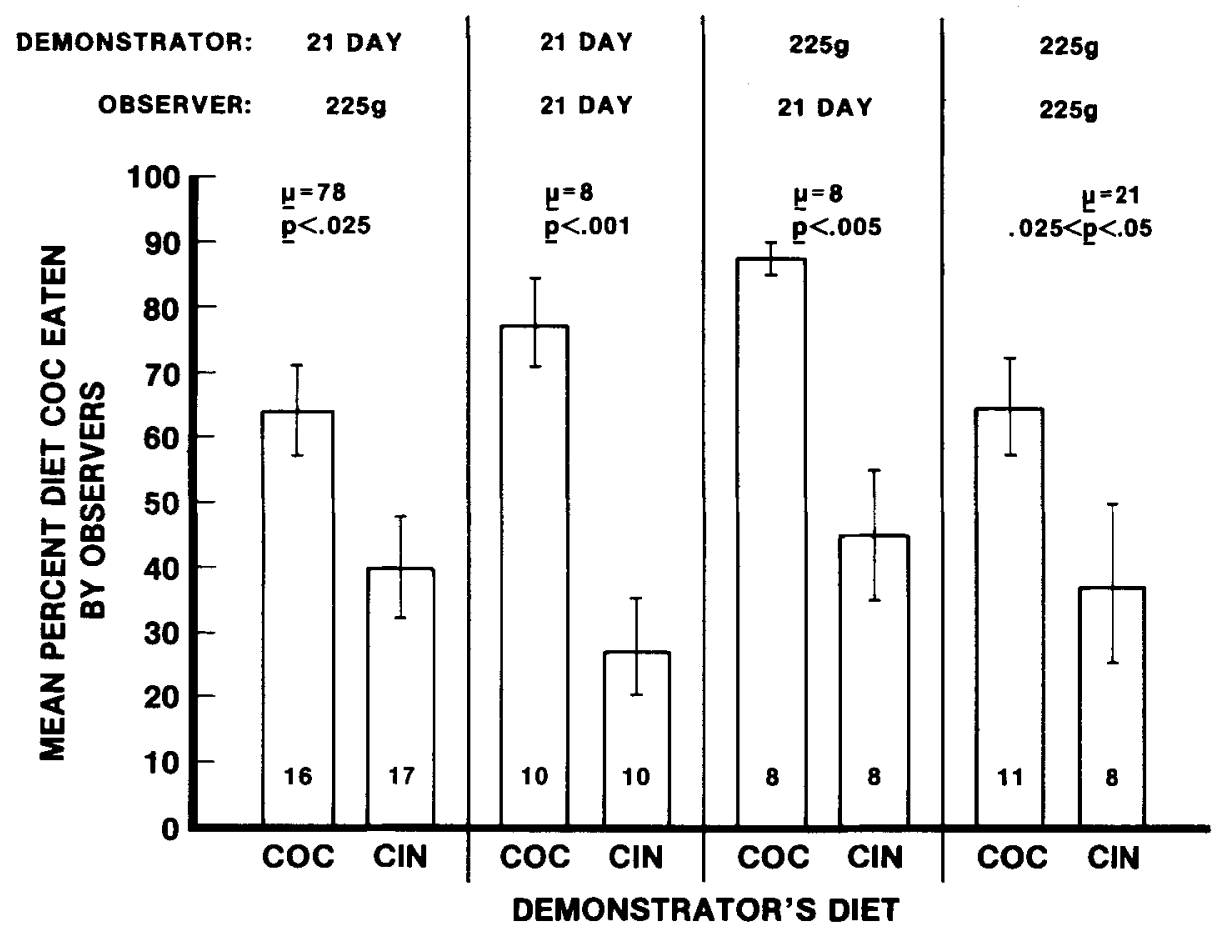

Figure 5. Mean amount of cocoa-flavored diet ingested, as a percentage of total amount eaten, by observers. (Bars indicate $\pm 1 \mathrm{SE}$; $\mathrm{Coc}=$ cocoa-flavored diet; $\mathrm{Cin}=$ cinnamon- flavored diet; numbers inside bars indicate group size.)

demonstrator influence on observer diet preference can be observed (1) in wild as well as domesticated rats, (2) in hungry as well as nondeprived observers, (3) in unfamiliar as well as familiar demonstrator-observer pairs, (4) in both weanling and adult rats, and (5) with respect to liquid as well as solid ingesta. In fact, we have been unable to discover any circumstance in which one might reasonably expect observers to acquire information from demonstrators in which they have not done so. Transmission of information concerning distant diets thus seems to be the most robust of the several mechanisms for social transmission of diet preference (Galef, 1977a, 1982) that we have explored to date.

\section{REFERENCES}

BARNETT, S. A. (1958). Experiments on "neophobia" in wild and laboratory rats. British Journal of Psychology, 49, 195-201.

GALEF, B. G., JR. (1970). Aggression and timidity: Responses to novelty in feral Norway rats. Journal of Comparative and Physiological Psychology, 70, 370-381.

GALEF, B. G., JR. (1977a). Mechanisms for the social transmission of food preferences from adult to weanling rats. In L. M. Barker, M. R.
Best, \& M. Domjan (Eds.), Learning mechanisms in food selection. Waco, TX: Baylor University Press.

GaLEF, B. G., JR. (1977b). Social transmission of food preferences: An adaptation for weaning in rats. Joumal of Comparative and Physiological Psychology, 91, 1136-1140.

GALEF, B. G., JR. (1978). Differences in affiliative behavior of weanling rats selecting eating and drinking sites. Journal of Comparative and Physiological Psychology, 92, 431-437.

GALEF, B. G., JR. (1982). Studies of social learning in Norway rats: A brief review. Developmental Psychobiology, 15, 279-295.

GALEF, B. G., JR. (1983). Utilization by Norway rats ( $R$. norvegicus) of multiple messages concerning distant diets. Joumal of Comparative Psychology, 97, 364-371.

GALEF, B. G., JR., \& Wigmore, S. W. (1983). Transfer of information concerning distant foods: A laboratory investigation of the 'information-centre' hypothesis. Animal Behaviour, 31, 748-758.

Galef, B. G., JR., Wigmore, S. W., \& KenNetT, D. J. (1983). A failure to find socially mediated taste aversion learning in Norway rats ( $R$. norvegicus). Journal of Comparative Psychology, 97, 358-363.

Posadas-Andrews, A., \& Roper, T. J. (1983). Social transmission of food preferences in adult rats. Animal Behaviour, 31, 265-271.

STRUPP, B. J. (1982). Malnutrition and animal models of cognitive development. Dissertation Abstracts International, 42, 4965-B. (University Microfilm No.821896).

(Manuscript received March 21, 1984; revision accepted for publication May 21, 1984). 